\title{
Eliminating Bus Stops: Evaluating Changes in Operations, Emissions and Coverage
}

\author{
Ranjay M. Shrestha and Edmund J. Zolnik \\ George Mason University
}

\begin{abstract}
Bus systems in the United States are unattractive to many potential riders because of their lack of efficiency, especially with regard to travel time. One of the reasons services are not more efficient has to do with the spacing of bus stops. After using a nearest facility algorithm with an $800 \mathrm{~m}$ walking distance threshold to identify eligible bus stops in the current bus system in the city of Fairfax, Virginia, the impacts of their elimination on operations, emissions, and coverage are estimated. Results indicate that eliminating some bus stops (about $40 \%$ of current stops) could improve travel times and reduce operating costs by the same percentage (23\%). In addition, bus-related emissions such as $\mathrm{CO}(34 \%), \mathrm{VOC}(18 \%)$, and $\mathrm{NO}_{x}(10 \%)$ could all be substantially lower. Surprisingly, the loss in coverage due to eliminating stops would not be large (10\% of the total population of the city of Fairfax).

\section{Introduction}

One of the reasons bus service in the United States is unpopular is because it is inefficient; it takes too long to get riders to their destinations. Many attribute this inefficiency to the spacing of bus stops (Furth et al. 2007). Densely-spaced bus stops improve geographic coverage and rider accessibility, but they also increase in-vehicle time and supply costs (Chien and Qin 2004). Sparsely-spaced bus stops,
\end{abstract}


on the other hand, yield faster services and lower operating costs even if ridership accessibility is lower (Murray and Wu 2003).

This study focused on bus service in the city of Fairfax, Virginia, also known as the City-University-Energysaver (CUE) bus system, which serves George Mason University (GMU). Currently, the CUE bus provides service to local residents and GMU students in the city of Fairfax who need access to campus as well as other modes of transportation such as light rail. The primary objective was to estimate the operating costs savings and emission reductions that could be realized by eliminating some stops on CUE bus routes. The secondary objective was to determine if it is possible to eliminate some CUE bus stops without adversely affecting service coverage. To meet the latter objective, equity and tradeoff analyses were performed by looking at the characteristics of stops and the people who would lose coverage if some of the stops on the current CUE bus routes were eliminated.

The second section provides background on bus stop spacing and the costs and benefits (economic, environmental, and social) of eliminating some of them. The third section discusses the data used in the study and the study area. The fourth section discusses the methods used to identify bus stops eligible for elimination and explores the service improvements which could result from their elimination. The fifth section presents the results of the study and the effect that eliminating some stops could have on the populations currently served by the CUE bus. The last section presents the conclusions of the study and avenues for future research.

\section{Background}

\section{Public Transportation Today}

The quality of bus service is perceived differently by different users. From the user's perspective, bus service quality is usually based on availability, frequency, travel speed, reliability and safety (Pratt 2000; Rood 1999; Phillips et al. 2001; Kittelson \& Associates 2003; Kihl et al. 2005; Marsden and Bonsall 2006; Litman 2007; 2008; Stradling et al. 2007; Kenworthy 2008). Although these are equally important for bus service evaluation, due to data availability and time constraints, this study evaluated the service quality improvements that could be realized by eliminating some stops on CUE bus routes in terms of travel time. In addition, it explored how operating costs, transit-based emissions, and population coverage would change if some CUE bus stops were eliminated. 


\section{Stop Spacing}

One way of improving the efficiency of bus service is via the appropriate spacing of stops. The proper spacing of stops can significantly improve the quality of bus service by decreasing travel times (Wirasinghe and Ghoneim 1981; Kocur and Hendrickson 1982; Fitzpatrick et al. 1997; Kuah and Perl 2001; Saka 2001; Chien and Qin 2004; Alterkawi 2006; Ziari et al. 2007). One of the key issues for determining the appropriate locations of bus stops is to have an understanding of how far people are willing to walk to get to the facilities (Ziari et al. 2007). Determining walking distance to and from bus stops presents two issues: knowledge of rider origins and destinations, and feasible walking distances along street networks (Furth et al. 2007).

One common method of identifying origins and destinations within bus service areas is to use the centroid of the population in those areas (Murray 2001; Saka 2001; Murray 2003; Furth et al. 2007). Because it is difficult to find the center of a population, the center points of individual blocks are often used to approximate population centers (Bielefeld et al. 1995; McElroy et al. 2003). Generating parcelbased centroid points using the parcel-network method would provide a highly detailed level of spatial accuracy regarding population coverage (Biba et al. 2010). However, due to a lack of parcel-level data, this study used block-level data to create service areas. Furthermore, unlike past research that used Euclidean distance to measure walking distances between origins and destinations (Okabe et al. 2008; Gutierrez and Gracia-Palomares 2008), the study used actual road network distances.

Another key issue is the appropriate walking distance to the facility. Accessibility to public transit is typically characterized as a reasonable walk under normal conditions (Murray 2003). Usually, facilities are located based on the simplified demand in the service areas (Wirasinghe and Ghoneim 1981; Brouwer 1983; Fitzpatrick et al. 1997). Others assume that it depends on population density-lower density corresponds to longer walking distances (Saka 2001; Ziari et al. 2007). Typical walking distances range from $400 \mathrm{~m}$ to $800 \mathrm{~m}$. In this study, different walking distances between $400 \mathrm{~m}$ and $800 \mathrm{~m}$ were used to see how they impact bus service coverage.

Calculating bus travel times is also important for measuring improvements in bus service. Two basic delay factors-dwell time and acceleration/deceleration timemake buses slower; that is, they increase total bus travel times (Saka 2001; Chien and Qin 2004; Ziari et al. 2007). Although Global Positioning Systems (GPS) and Geographic Information Systems (GIS) are frequently used to estimate these delays 
(Srinivasan and Jovanis 1996; Hellinga and Fu 1999), the study used different delay variables to calculate them.

\section{Costs and Benefits}

Besides understanding the primary benefit of more efficient travel times that could be achieved by eliminating bus stops, it is also important to understand what other costs and benefits could be associated with this course of action (Savage 2009). This is known as impact analysis and entails an analysis of the impacts of changing transit services (Litman 2004). Research on public transit system improvements tends to adopt different perspectives. Most focus on the economic, environmental, and spatial effects of improving public transit service (Polzin 1999; Kennedy 2002; Bento et al. 2005; Brownstone and Small 2005; Harford 2006). Therefore, this study focused on the following tradeoffs of improved service on the CUE bus: economic effects (operating cost reductions), environmental effects (emission reductions), and spatial effects (residential service coverage). By analyzing the tradeoffs of reduced travel times that could be achieved by eliminating stops on the CUE bus routes, the study estimated the different impacts that could result from the change in transit service.

\section{Economic Effects: Operating Cost Reductions}

There are various ways to perform an economic analysis of a bus system. However, to estimate the financial impacts of two different routes, the differences in their operating costs provide a direct monetary comparison (Karlaftis and McCarthy 1999). Benjamin and Obeng (1990) found that reductions in operating costs for public transit could be achieved by increasing vehicle efficiency. In the United States, all operating costs that are not covered by bus fares come from either taxation through dedicated revenues or local, state, and federal government taxderived monies (Harford 2006). It was, therefore, important to understand the financial savings that could be achieved by eliminating some stops on the CUE bus system.

\section{Environmental Effects: GHG Emissions Reductions}

Transportation is one of the major contributors to air pollution in the United States. Among the different sources of air pollution, on-road vehicle emissions are responsible for about 45 percent of the Environmental Protections Agency's (EPA's) 6 criteria pollutants (National Research Council 1995). Of the different greenhouse gases (GHGs) emitted by vehicles, carbon monoxide (CO), volatile organic compounds (VOCs), and nitrogen oxide $\left(\mathrm{NO}_{\mathrm{x}}\right)$ contribute the most (Grant et al. 
2007). CO and VOCs are emitted from the incomplete combustion of fossil fuels, whereas $\mathrm{NO}_{\mathrm{x}}$ is the product of high-temperature chemical processes that occur during the combustion process in the engine itself (National Research Council 1991). Even though emissions from diesel-fueled vehicles such as buses are only five percent of on-road vehicle emissions, emission rates for such heavy-duty vehicles are higher since they operate at higher combustion pressures and temperatures than gasoline-fueled vehicles (Lilly 1984). This means that even though their relative contribution to on-road vehicle emissions is limited, heavy-duty vehicles such as buses are highly hazardous to the environment. This study, therefore, explored the environmental benefits that could be realized by eliminating stops on CUE bus routes in terms of GHG emission reductions.

There are many ways to measure the amount of GHGs emitted by different types of vehicles. In fact, vehicle emissions are a function of several variables grouped into four main categories: travel-related factors, driver behavior, highway network characteristics, and vehicle characteristics (National Research Council 1995). In this study, only travel-related factors varied between the old (all current stops) and the new (without some stops) CUE bus routes, whereas the rest of the variables (driver behavior, highway network characteristics, and vehicle characteristics) remained the same. Travel-related factors included trip/vehicle use and speed/acceleration, which were used to calculate and compare the emissions between the two routes (National Research Council 1995). Trip/vehicle use emissions are simply a function of the total number of trips and total distance traveled by the vehicle. Speed/ acceleration emissions are a function of the speed and acceleration of the vehicle over the distance of the trip. Eliminating some bus stops will yield improvements only in the travel speeds of buses. This means that other travel-related factors such as vehicle miles traveled and numbers of trips will not be affected by eliminating some bus stops. This study, therefore, used only the speed/acceleration factor to calculate and compare the emissions differences between the old and the new CUE bus routes.

\section{Spatial Effects: Residential Service Coverage}

Eliminating some stops on the CUE bus routes could have an effect on residential service coverage. It was, therefore, important to explore the characteristics of riders who use the CUE bus to evaluate the costs of eliminating some of the bus stops that serve them. Exploring the demographic profiles of riders also helps to characterize the people who use public transit (Neff and Pham 2007) and derive 
a relationship between public transit and the people that could be affected by changes in service (Polzin 1999).

\section{Data}

\section{GMU Commuting Survey}

GMU conducted a survey of faculty/staff and students in 2007 to better understand their commuting behavior. They were particularly interested in the factors that most influenced mode choices to campus for those living in the city of Fairfax. Results suggest that among 1,000 respondents, more than 75 percent of those who lived up to six miles from campus reported that commuting time was one of the main reasons for driving to campus. They further felt that current CUE bus service was not efficient enough, especially with respect to travel times.

\section{Data Sources}

Demographic data for the block groups in the study area are from the United States Bureau of the Census. Block group boundaries and road network data are from Environmental Systems Research Institute (ESRI). Two CUE bus routes (Gold and Green) along with their corresponding bus stops were created from the road network data from ESRI. Current CUE bus travel times and schedules were obtained from the City of Fairfax. Financial information on the CUE bus service for the year 2008 are from the National Transit Database (2008). The data include different operational and non-operational expenditures associated with the CUE bus service. Information on the fuel types used on the CUE buses was from the City of Fairfax. For the GHG emissions estimates, factors based on the speed of the CUE buses are from the Metropolitan Washington Council of Governments (MWCOG) (2010).

\section{Study Area}

The study area included the block groups served by the CUE bus routes within the city of Fairfax. In addition, several block groups from within the jurisdiction of Fairfax County were included because they are also served by CUE bus routes. Two of these block groups from within Fairfax County include GMU and the Vienna/ Fairfax-GMU Metro station, which is the last westbound stop on the Orange Line. Figure 1 is a map of the study area including the CUE bus routes. 


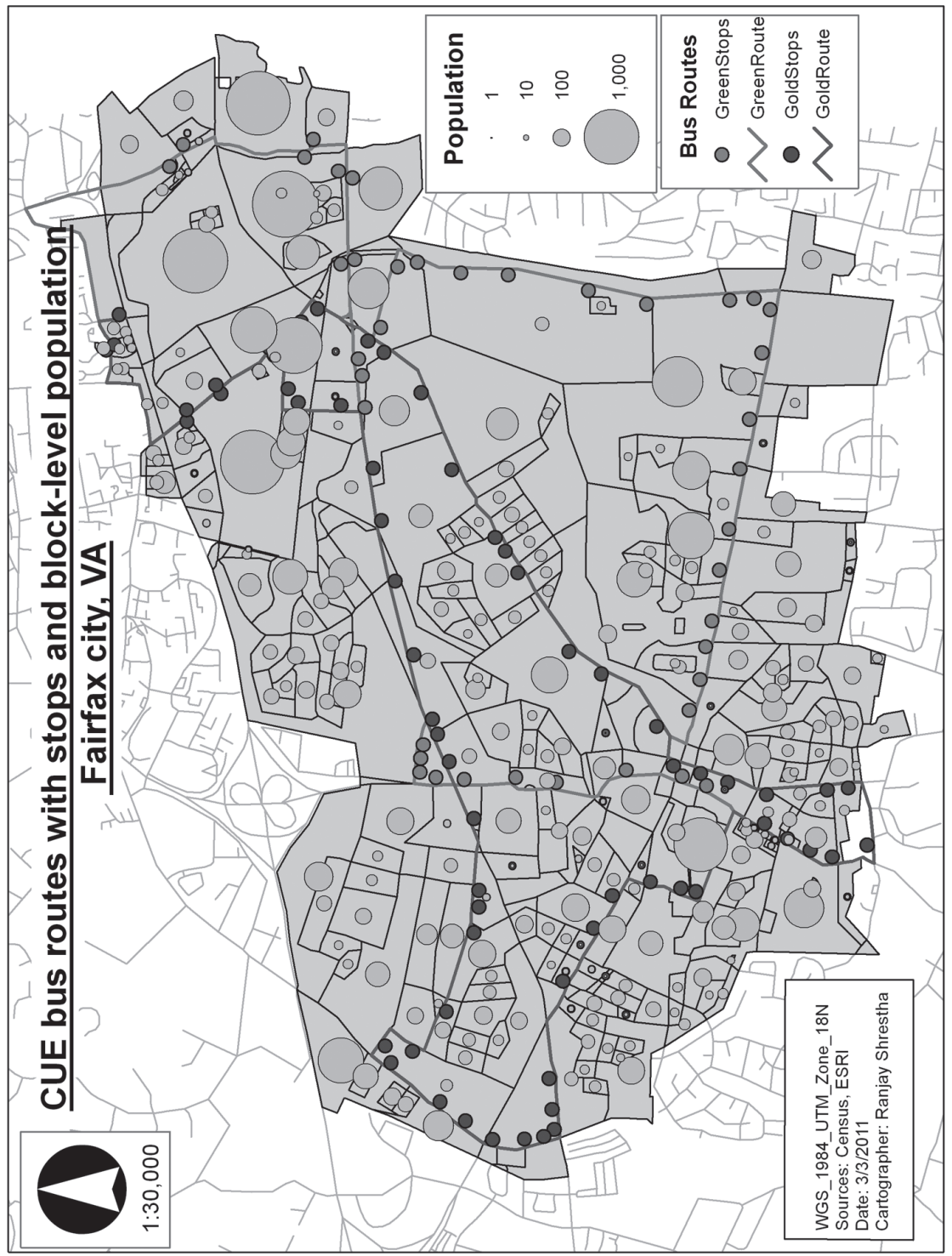

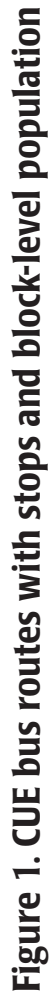




\section{Methods}

\section{Equity Analysis}

It appeared that analyzing the tradeoffs of eliminating some stops on the CUE bus routes may be amenable to standard cost-benefit analysis (Litman 2009). However, further reflection revealed that some of the costs of eliminating some stops was not easily monetized. For example, costs attributable to shrunken residential service coverage are usually classified as social costs. Monetizing such social costs is difficult. Therefore, standard cost-benefit analysis may not provide an accurate estimate of the tradeoffs related to residential service coverage.

One way to account for such social costs is via equity analysis (Litman and Doherty 2009). In simple terms, equity refers to the distribution of various social and/or economic impacts and whether those distributions are considered appropriate (Litman 2002). Equity analysis generally is considered a complicated procedure, as there is no single way to evaluate equity. Evaluation usually depends on the type of equity, the way people are categorized, which impacts are considered, and how equity is measured.

In the study, transportation equity was measured by the reduction in operating costs, the reduction in GHG emissions and the improvement in overall fleet speed that could result from eliminating some stops on the CUE bus routes. Access to bus service was measured by estimating the extent of the changes in residential service coverage that could result from eliminating some stops on the CUE bus routes. Additionally, the demographic profiles of the residents who would no longer be serviced by the CUE bus routes after their stops had been eliminated was also taken into consideration in the equity analysis. This helped to assess the potential social costs of eliminating some of the stops on the CUE bus routes.

\section{Walking Distance Thresholds}

Using block group centroids to represent service areas and bus stops to represent facilities, a network analysis was undertaken to find the nearest facilities within different walking distances from the centroids. The network analysis used a shortest path algorithm to find the closest facility for each service area. In less denselypopulated areas, such as the city of Fairfax, the most realistic walking distance threshold is $800 \mathrm{~m}$ (Demetsky and Lin 1982; Saka 2001; Ziari et al. 2007). It is also the most conservative walking distance threshold, given that most riders in North America (75-80\%) walk $400 \mathrm{~m}$ or less to bus stops (Kittelson \& Associates 2003). However, to better understand how different walking distances change residential 
service coverage, walking distances of $200 \mathrm{~m}, 400 \mathrm{~m}$ and $600 \mathrm{~m}$ were also tested. In addition, the network analysis was undertaken without any walking distance threshold to ensure that all of the service areas were covered. This latter analysis offered a glimpse of the maximum number of facilities required to provide complete coverage in the study area.

\section{Eliminating Bus Stops}

After undertaking the nearest facility analysis for all five walking distance thresholds ( $200 \mathrm{~m}, 400 \mathrm{~m}, 600 \mathrm{~m}, 800 \mathrm{~m}$ and none), the minimum number of bus stops used at each walking distance was obtained. Those facilities that were not selected at any of the walking distance thresholds were assumed to be eligible for elimination. The reasons that some bus stops were never selected, no matter the walking distance threshold, was because some of the census block centroids were beyond the maximum walking distance threshold $(800 \mathrm{~m}$ ) or the closest census block centroid was already served by another bus stop. In either case, those bus stops that were never selected were labeled as eligible for elimination. Figure 2 is a map of the study area including the CUE bus routes and the stops that were eliminated.

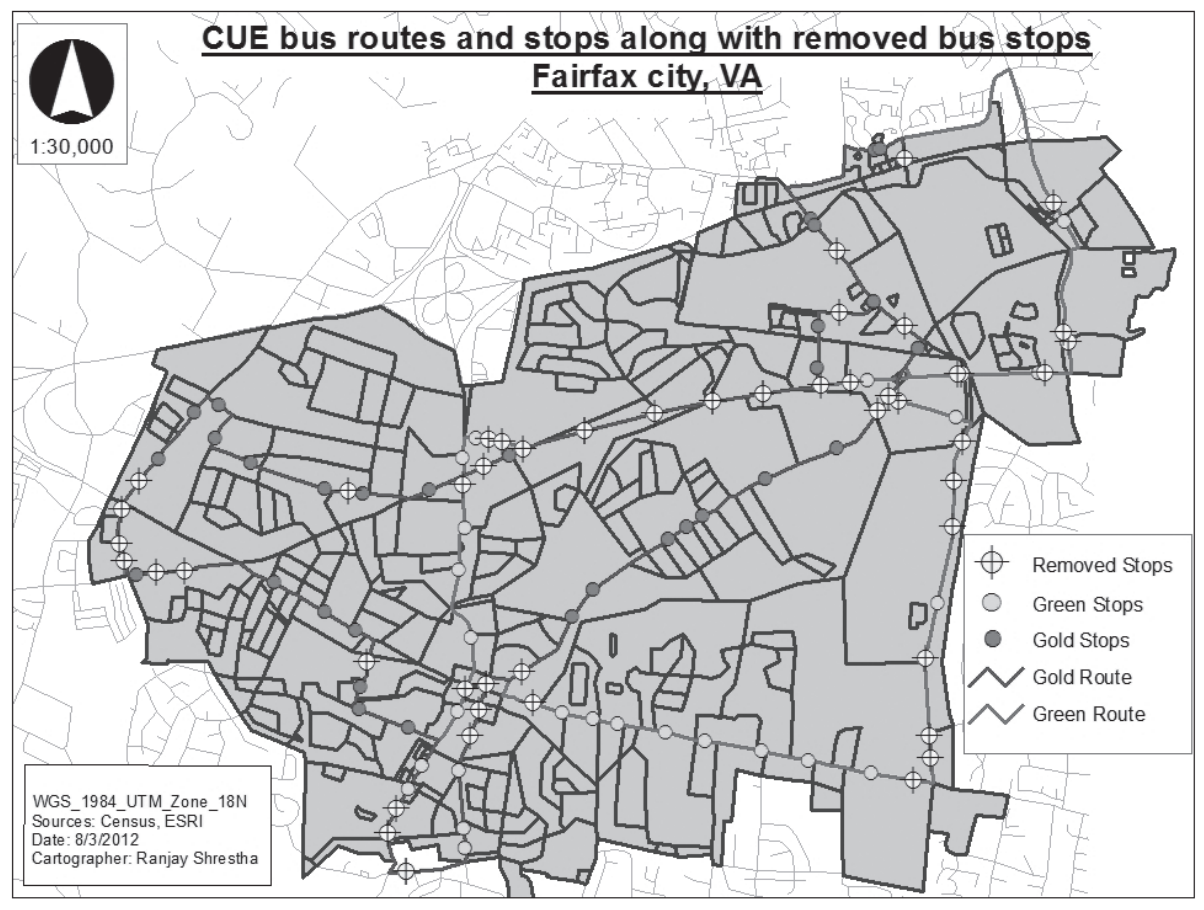

Figure 2. CUE bus routes, stops, and eliminated bus stops 
Based on previous research (Demetsky and Lin 1982; Saka 2001; Murray 2003; Ziari et al. 2007) and given that many of the block groups in the study area are sparsely populated, $800 \mathrm{~m}$ was an appropriate walking distance benchmark for the study. Using the $800 \mathrm{~m}$ walking distance threshold, therefore, those bus stops that were not selected were eliminated from the CUE bus routes.

\section{Bus Stop Delays}

Two factors that contribute significantly to time delays at bus stops are acceleration/deceleration delay and dwell time delay. These delays can consume up to 26 percent of total bus travel times (Rajbhandari et al. 2003). Acceleration/deceleration delay occurs when the bus is pulling in or out of the bus stop. Dwell time delay refers to the time delay to load and unload riders at bus stops. The two factors are calculated from the following equations (Saka 2001; Chien and Qin 2004; Ziari et al. 2007). The first equation calculates the time delay due to decelerating/accelerating:

$$
T_{\text {accldec }}=\left(\frac{V}{a c c}\right)+\left(\frac{V}{d e c}\right),
$$

where

$$
\begin{aligned}
& T_{\text {acc/dec }}=\text { acceleration } / \text { deceleration delay } \\
& V=\text { bus cruising speed }(\mathrm{m} / \mathrm{s}) \\
& a c c=\text { bus acceleration }\left(\mathrm{m} / \mathrm{s}^{2}\right) \\
& d e c=\text { bus deceleration }\left(\mathrm{m} / \mathrm{s}^{2}\right)
\end{aligned}
$$

By multiplying the total number of riders by the dwell delay for each rider, the following equation calculates the total dwell time delay for each bus stop:

$$
T_{W}=Q \times w,
$$

where

$T_{w}=$ dwell time delay (s)

$Q=$ number of riders at the stop

$w=$ time to board/unboard each rider

Cruise speed $(V)$ and acceleration/deceleration (acc/dec) were from the current CUE bus schedule. The cruise speed was about $12 \mathrm{~m} / \mathrm{s}$ ( $27 \mathrm{mi} / \mathrm{hr}$ ), and acceleration and deceleration was about $2 \mathrm{~m} / \mathrm{s}^{2}$ (Furth and SanClemente 2006). Data for 
other time delay variables were from direct observation on the CUE bus: the average number of riders at the stops $(Q)$ was 4; and the time to board/unboard each riders $(w)$ was $5 \mathrm{~s}$. Using the above equations and data, the time delay at each stop on the CUE bus route $\left(T_{w}\right)$ was $20 \mathrm{~s}$. It is important to note that this time delay was based on an observed number of riders per stop who on-boarded and off-boarded the CUE bus. Because it was an average for all stops, it masked differences between stops in the number of riders who on- and off-boarded the bus, the speed with which subsequent riders were able to board the bus after the initial rider boards the bus and the effects of near- and far-side stops on time delays. Each of these issues was important in the calculation and sensitivity of the time delay estimates and is, therefore, worthy of future research.

\section{Total Travel Time}

The following equation calculates total travel time for the new bus routes (Saka 2001):

$$
T_{b u s}=N \times\left(T_{a c c / d e c}+T_{W}\right)+T_{V},
$$

where

$T_{\text {bus }}=$ total bus travel time

$N=$ total number of bus stops

$T_{v}=$ time for CUE bus to make a one-way trip at cruise speed (s)

Total travel time is the time it took the CUE bus to make a one-way trip on the new and old routes. The first part of the equation calculated the total delay at each stop; multiplying that expression by the total number of stops $(N)$ resulted in the total delay for a one-way trip. The total delay depends on the number of stops on the route. Using the network analyst tool in GIS, the total route distance estimate was $42,890 \mathrm{~m}$ ( $26.65 \mathrm{mi}$ ). Therefore, the time for the CUE bus to make a one-way trip at cruise speed $\left(T_{v}\right)$ was $3,574.16 \mathrm{~s}$. Using Eq. (3), the total travel time for both the old and the new CUE bus routes was calculated. The number of bus stops on the old CUE bus route was 121, and the number of bus stops on the new CUE bus route was 68 . One assumption of Eq. (3) is that the CUE bus does not skip any of the available stops on either the new or the old routes-an assumption that is not realistic. This means that the total travel time estimates from Eq. (3) for the new and old routes would be higher than the observed total travel times, given that the CUE bus was already making one-way trips faster than expected. 


\section{Operating Cost Reductions}

Annual operating cost data for the CUE bus are from the National Transit Database (2008). The database includes operating costs for the CUE bus from 2001 to 2008. However, only operating costs for the year 2008 appear in the study to reflect the most recent expenditures. Annual operating costs are in four different categories: operations, maintenance, non-vehicle, and general administrative. Operations costs include operator's wages, fringe benefits and services. Maintenance costs include fuel and lube, tires, and other. Non-vehicle costs include casualty and liabilities and utilities. Administrative costs include other wages and salaries. Vehicle fleet size is the total number of vehicles available for operations in a given year. Vehicle revenue hour is the hours that vehicles are scheduled for or actually are in revenue service (including layovers and recovery times).

A simple mathematical approach to estimate the total operating costs is to sum all of the costs and then divide by the Vehicle Revenue Hour (VRH), which was $\$ 34,602$, to get the total cost per hour to operate the CUE bus (Bruun 2005). Following this approach, total operating costs (TOC) and total operating costs per hour $(\mathrm{TOCH})$ were $\$ 2,980,627$ and $\$ 86.14$, respectively. TOCH provides a calculation of total operating costs for any given hour of operating the CUE bus. However, it may not accurately reflect total operating costs for the purposes of the study. One of the objectives of the study was to estimate the cost savings in operating the CUE bus that could be realized by eliminating some stops on the route. To that end, some of the subcategories of costs, such as administrative salaries, operations fringe benefits and non-vehicle casualties and liabilities would not be affected by the elimination of some CUE bus stops. The exclusion of the above costs from the calculation of the TOC and TOCH, therefore, provided a more accurate calculation of the costs of operating the CUE bus for the study. The more accurate TOC and TOCH were $\$ 1,791,127$ and $\$ 51.76$, respectively.

\section{Emissions Reductions}

To calculate CUE bus emissions at cruise speed, emissions factors for diesel buses from the Metropolitan Washington Council of Governments (2010) and the United States Environmental Protection Agency (2003) were used. MWCOG's approach is based on the EPA's Mobile6 emissions factors model, which estimates emissions factors based on the average speed of diesel buses. It calculates CO, VOCs, and $\mathrm{NO}_{x}$-including both $\mathrm{NO}$ and $\mathrm{NO}_{2}$-depending on average vehicle speed. Even though emissions factors were available from 1990 to 2005, only data for the most recent year were used to make it timelier. 
The emissions analysis in the study would be more accurate if carbon dioxide $\left(\mathrm{CO}_{2}\right)$ emissions were included. However, because sufficient information on the speed of the vehicle was not available, only $\mathrm{CO}, \mathrm{VOC}$, and $\mathrm{NO}_{\mathrm{x}}$ emissions were calculated in the study. Besides, $\mathrm{CO}, \mathrm{VOC}$, and $\mathrm{NO}_{x}$ are the predominant air pollutants from road transportation sources (Grant et al. 2007). On average, in the United States, road transportation sources are responsible for 55 percent of $\mathrm{CO}, 27$ percent of $\mathrm{VOC}$, and 35 percent of $\mathrm{NO}_{x}$ towards overall GHG emissions.

As mentioned above, the total, one-way route distance for the CUE bus was 42,890 $\mathrm{m}(26.65 \mathrm{mi})$ and the total, one-way travel time for the CUE bus was 7,440 s (2.07 $\mathrm{hr}$ ). Therefore, the cruise speed of the bus was $\sim 13 \mathrm{mi} / \mathrm{hr}$. With this information and the emissions factors from MWCOG, the following equation calculated $\mathrm{CO}, \mathrm{VOC}$, and $\mathrm{NO}_{\mathrm{x}}$ emissions from the CUE bus at different cruise speeds:

$$
E=E F \times D,
$$

where

$$
\begin{aligned}
& E=\mathrm{CO}, \mathrm{VOC}, \text { or } \mathrm{NO}_{\mathrm{x}} \text { emissions }(\mathrm{g}) \\
& E F=\mathrm{CO}, \mathrm{VOC}, \text { or } \mathrm{NO}_{\mathrm{x}} \text { emissions factors at different speeds }(\mathrm{g} / \mathrm{mi}) \\
& D=\text { total CUE bus route distance }(\mathrm{mi})
\end{aligned}
$$

The results section shows the calculations for emissions reductions that could be realized after eliminating some of the stops on the CUE bus route.

\section{Results}

\section{Travel Time Reduction}

Table 1 shows how facility usage and service area coverage would change at different walking distance thresholds. Clearly, eliminating some CUE bus stops has the potential to reduce travel times without unduly affecting service area coverage. At the ideal walking distance threshold $(800 \mathrm{~m}), 56.2$ percent of the available facilities were used, but fully 82.5 percent of the service area was covered. This translates to a potential travel time reduction of 23 percent (approximately $28 \mathrm{~min}$ ) (Table 2). It is important to qualify this estimate because it assumes, as mentioned above, that the CUE bus stops at all available stops. This is not likely, especially during the summer when demand is lower than during the fall and spring semesters. This means that the potential travel time reduction would probably be less than $28 \mathrm{~min}$ because the CUE buses would already be skipping some stops. 
Table 1. Facility Usage and Service Area Coverage at Different Walking Distance Thresholds

\begin{tabular}{|c|c|c|c|c|c|c|}
\hline $\begin{array}{c}\text { Walking Distance } \\
\text { Threshold (m) }\end{array}$ & $\begin{array}{c}\text { Total } \\
\text { Facilities }\end{array}$ & $\begin{array}{c}\text { Facilities } \\
\text { Used }\end{array}$ & $\begin{array}{c}\text { Facilities } \\
\text { Used (\%) }\end{array}$ & $\begin{array}{c}\text { Total } \\
\text { Area (acs) }\end{array}$ & $\begin{array}{c}\text { Service } \\
\text { Area (acs) }\end{array}$ & $\begin{array}{c}\text { Service } \\
\text { Area (\%) }\end{array}$ \\
\hline 200 & 121 & 29 & 24.0 & 251 & 51 & 20.3 \\
\hline 400 & 121 & 52 & 43.0 & 251 & 112 & 44.6 \\
\hline 600 & 121 & 66 & 54.5 & 251 & 177 & 70.5 \\
\hline 800 & 121 & 68 & 56.2 & 251 & 207 & 82.5 \\
\hline None & 121 & 71 & 58.7 & 251 & 249 & 99.2 \\
\hline
\end{tabular}

Table 2. Travel Time Reduction between Old and New CUE Bus Routes

\begin{tabular}{|c|c|c|c|}
\hline CUE Bus Route & Stops (n) & Total Delay (s) & Total Travel Time (s) \\
\hline Old & 121 & 3,872 & 7,446 \\
\hline New & 68 & 2,176 & 5,750 \\
\hline \multicolumn{4}{|r}{ Reduction (\%) } \\
\hline
\end{tabular}

\section{Operating Cost Reduction}

The impressive travel time reduction means that operating costs could also be reduced by eliminating some of the CUE bus stops. The total operating cost per hour (TOCH) for the CUE bus was $\$ 51.76$. Multiplying TOCH by the old and new total travel times (2.07 hrs and $1.60 \mathrm{hrs}$, respectively), the old and new operating costs were $\$ 108.70$ and $\$ 82.82$, respectively. Overall operating costs for single, oneway trips by CUE buses could therefore be reduced by $\$ 25.88$ if some of the stops were eliminated. Because CUE buses made 312 trips per week, the total weekly projected operating cost reduction would be $\$ 8,074.56$.

\section{Emissions Reductions}

Using Eq. (4) and the emissions factors for diesel buses, the GHG emissions reductions that could be realized by eliminating some CUE bus stops are as follows. For the old route with a cruise speed of $13 \mathrm{mi} / \mathrm{hr}$, emissions of $\mathrm{CO}, \mathrm{VOC}$, and $\mathrm{NO}_{\mathrm{x}}$ are $1.23 \mathrm{lb}, 0.11 \mathrm{lb}$, and $1.21 \mathrm{lb}$, respectively. For the new route with a cruise speed of 17 $\mathrm{mi} / \mathrm{hr}$, emissions of $\mathrm{CO}, \mathrm{VOC}$, and $\mathrm{NO}_{x}$ are $0.82 \mathrm{lb}, 0.09 \mathrm{lb}$ and $1.09 \mathrm{lb}$, respectively. GHG emissions could, therefore, be reduced by eliminating some of the stops on the CUE bus-CO could be reduced by 33.34 percent, VOC could be reduced by 18.18 percent, and $\mathrm{NO}_{x}$ could be reduced by 9.92 percent. Interestingly, Table 3 and Figure 3 show that annual emissions of the GHG emissions $\mathrm{CO}$ and $\mathrm{NO}_{x}$ would 
decrease the most over the range of eliminated stops on the CUE bus ( 0 to 53 stops eliminated).

Table 3. Number of Stops Eliminated and Changes in Population, Costs, Travel Times, and Emissions

\begin{tabular}{|c|c|c|c|c|c|c|}
\hline \multirow{2}{*}{$\begin{array}{c}\text { Stops } \\
\text { Eliminated } \\
(n)\end{array}$} & \multirow{2}{*}{$\begin{array}{c}\text { Population } \\
\text { Coverage } \\
(\%) \\
\end{array}$} & \multirow{2}{*}{$\begin{array}{l}\text { Annual Cost } \\
\text { Reduction } \\
\text { (\$) }\end{array}$} & \multirow{2}{*}{$\begin{array}{l}\text { Travel Time } \\
\text { Reduction } \\
\text { (min) }\end{array}$} & \multicolumn{3}{|c|}{ Emissions (lb/yr) } \\
\hline & & & & $\mathrm{CO}$ & VOC & $\mathrm{NO}_{\mathrm{x}}$ \\
\hline 53 & 89 & $407,517.59$ & 29 & $12,292.60$ & $1,360.97$ & $16,252.57$ \\
\hline 50 & 99 & $384,450.56$ & 27 & $13,610.76$ & $1,402.32$ & $16,549.06$ \\
\hline 30 & 99 & $230,670.34$ & 16 & $16,896.57$ & $1,506.39$ & $17,280.78$ \\
\hline 20 & 99 & $153,780.22$ & 11 & $17,508.31$ & $1,543.10$ & $17,589.71$ \\
\hline 10 & 99 & $76,890.11$ & 5 & $18,065.10$ & $1,576.50$ & $17,870.89$ \\
\hline 5 & 99 & $38,445.06$ & 3 & $18,325.16$ & $1,592.11$ & $18,002.22$ \\
\hline 0 & 99 & 0.00 & 0 & $18,472.43$ & $1,600.94$ & $18,076.59$ \\
\hline
\end{tabular}

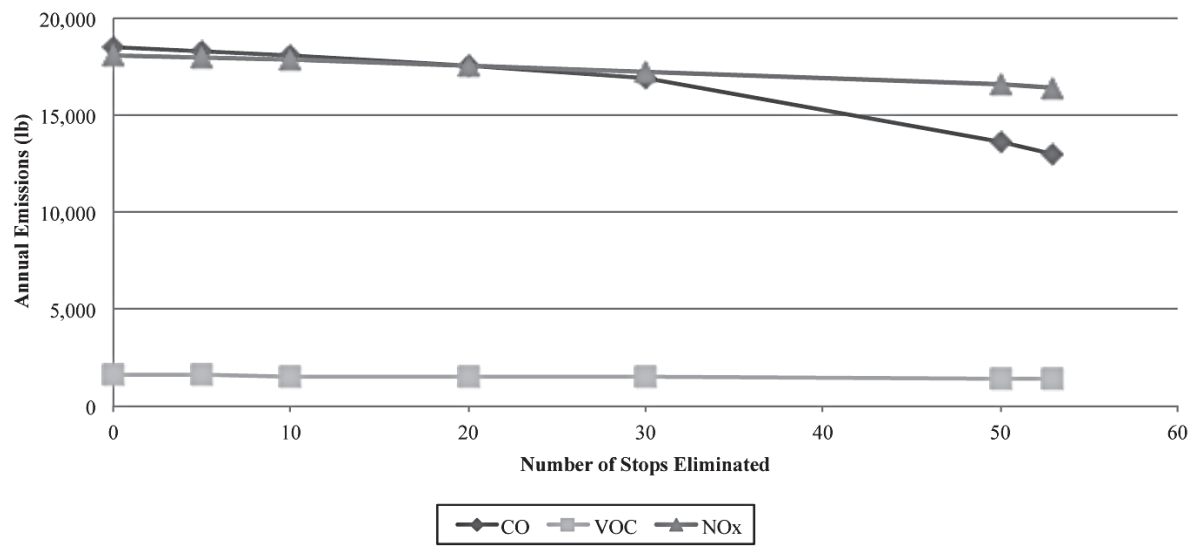

Figure 3. Changes in annual emissions by number of stops eliminated 


\section{Tradeoffs}

\section{Eliminated Bus Stops by Category}

All of the CUE bus stops, both eliminated and retained, were categorized as either commercial, recreational, residential or shopping stops. The categorization of bus stops was based on inspection of the CUE bus route map and observations from riding the CUE bus. Stops close to major commercial landmarks such as restaurants, banks, metro stations and schools were categorized as commercial stops. Stops close to housing units were categorized as residential stops and stops close to park and recreational facilities are categorized as recreational stops. Finally, stops close to shopping centers were categorized as shopping stops. Table 4 shows the tally of these bus stops. Among the 53 bus stops that were eliminated from the old route, 15 were commercial, 21 were recreational, 3 were residential, and 14 were shopping stops. Similarly, among the 68 bus stops that were retained from the old route, 35 were commercial, 10 were recreational, 3 were residential, and 20 were shopping stops.

\section{Table 4. Categorization of Eliminated and Retained Stops}

\begin{tabular}{|l|c|c|c|}
\hline \multirow{2}{*}{ Category } & \multicolumn{3}{|c|}{ Stops } \\
\cline { 2 - 4 } & Eliminated & Retained & Total \\
\hline Commercial & 14 & 20 & 34 \\
\hline Recreational & 3 & 3 & 6 \\
\hline Residential & 15 & 35 & 50 \\
\hline Shopping & 21 & 10 & 31 \\
\hline Total & 53 & 68 & 121 \\
\hline
\end{tabular}

Looking further into the categories of bus stops that were eliminated, 68 percent $([21 \div 31] \times 100 \%)$ of the shopping stops were eliminated. Furthermore, 41 percent $([14 \div 34] \times 100 \%)$ and 30 percent $([15 \div 5] 0 \times 100 \%)$ of the commercial and residential stops, respectively, were eliminated. Fifty percent $([3 \div 6] \times 100 \%)$ of the recreational stops were eliminated, but because recreational stops make up such a small percentage of all CUE bus stops $([6 \div 121] \times 100 \%=5 \%)$, the loss of recreational stops was actually small. The loss of shopping stops means that residents would have to walk further to either the next nearest bus stop or to the shopping center itself. However, because most people do not use public transit for shopping trips, particularly food shopping trips, the elimination of these stops would not be as significant as it first appears. 


\section{Residential Service Coverage}

One difficulty of capturing the residential population that lives within proximity of the eliminated bus stops was choosing the appropriate buffer distance between the bus stop and the population center. Murray (2003) suggested that $400 \mathrm{~m}$ would be an ideal buffer distance for a city area to estimate the effect of eliminating bus stops. Others have suggested suitable buffer distances from $200 \mathrm{~m}$ to 300 $\mathrm{m}$ (Ziari et al. 2007). In this study, a middling buffer distance of $300 \mathrm{~m}$ was used to capture the population that would be most affected by the elimination of some CUE bus stops.

The coverage analysis using a $300 \mathrm{~m}$ buffer distance around the 15 residential bus stops that were eliminated shows that 3,588 residents (approximately $10 \%$ of the city of Fairfax's population) would be affected. The demographic analysis on the residential population was further broken down into various racial groups living within proximity of the eliminated bus stops. White residents (57\%) would be most affected, followed by Hispanic (20\%), Asian (15\%), and African American (5\%) residents. Other residents, including Native Americans and Asian and Pacific Islanders, made up the remaining 3 percent of the affected resident population. Further demographic analysis shows that none of these racial groups would be disproportionately affected by eliminating those 15 bus stops.

Residents living within proximity of the eliminated bus stops who are members of other groups may also be adversely affected. In particular, residents who are 65 years of age or older and no longer participating in the labor force may prefer more accessible stops over faster bus service. For these residents, time is not as important as access. Demographic analysis on the resident population, however, showed that few residents in the study area were 65 years or older. This is consistent with the housing pattern at the Fairfax campus of George Mason University, where offcampus accommodations for undergraduate and graduate students makes up for a lack of on-campus accommodations. This also makes the results of the study less generalizable to different geographies with a more balanced demographic profile of younger and older residents.

\section{Conclusions}

According to our model, eliminating some of the stops on the current CUE bus route could reduce one-way travel times and operating costs by a projected 23 percent. The observed magnitude of the travel time reductions needs to be verified with data on speed differences based on bus stop densities; however, improving 
travel times would boost ridership. In addition, savings from lower operating costs could be used to improve other aspects of the CUE bus service (for example, reducing fares or improving bus stop facilities) to further boost ridership. In addition to the operations benefits, eliminating some bus stops would be good for the environment. The new route could reduce GHG emissions of $\mathrm{CO}, \mathrm{VOC}$, and $\mathrm{NO}_{x}$ by 34,18 and 10 percent, respectively. On average, the new route could reduce annual GHG emissions of $\mathrm{CO}, \mathrm{VOC}$, and $\mathrm{NO}_{x}$ by $6,278,241$, and 1,789 lbs, respectively. For year 2008 , the total amount of on-road vehicle emissions nationwide of CO, VOC and $\mathrm{NO}_{x}$ was approximately 38, 2.5 and 4.2 mil tons (United States Environmental Protection Agency 2009). While the potential GHG emissions reductions that could result from eliminating some stops on the CUE bus route may pale in comparison to nationwide GHG emissions, these reductions would be significant for the city of Fairfax. Finally, only 10 percent of the resident population of Fairfax would be directly affected by eliminating some of the CUE bus stops. This latter finding suggests that resident service coverage would likely not be a problem.

Transit riders are sensitive to comfort and convenience improvements in service (Phillips et al. 2001; Litman 2004; Litman 2008). And, surely, they are sensitive to the elimination of service. One limitation of the study, therefore, is that the tradeoff of lost ridership due to the elimination of more accessible bus stops was not taken into consideration. For example, the policy of the CUE bus is not to stop between stops to load or unload riders. This policy could raise objections from riders who are fearful of walking longer distances to the next nearest bus stop, especially in the dark (though adoption of a more flexible policy to stop at night between stops could address such objections). Another limitation is that the study did not attempt to account for the potentially adverse effects that eliminating some CUE bus stops could have on commercial, recreational and shopping trips by residents. These trips are important for households in the service area who do not have private vehicles. Surveys of CUE bus riders could help to address these limitations and ultimately provide a more detailed assessment of the potential tradeoffs of eliminating some CUE bus stops.

\section{References}

Alterkawi, M. 2006. A computer simulation analysis for optimizing bus stops spacing: The case of Riyadh, Saudi Arabia. Habitat International 30(3): 500-508. 
Benjamin, J., and K. Obeng. 1990. The effect of policy and background variables on total factor productivity for public transit. Transportation Research Part B: Methodological 24(1): 1-14.

Bento, A., M. Cropper, A. Mobara, and K. Vinha. 2005. The effects of urban spatial structure on travel demand in the United States. Review of Economics and Statistics 87(3): 466-478.

Biba, S., K. Curtin, and G. Manca. 2010. A new method for determining the population with walking access to transit. International Journal of Geographic Information Science 24(3): 347-364.

Bielefeld, W., J. Murdoch, and P. Waddell. 1995. The influence of demographics and distance on nonprofit location. Nonprofit and Voluntary Sector Quarterly 26(2): 207-225.

Brouwer, P. 1983. Position and design of bus stops in urban areas. UITP Revue 32(1): 74-86.

Brownstone, D., and K. Small. 2005. Valuing time and reliability: Assessing the evidence from road pricing demonstrations. Transportation Research Part A: Policy and Practice 39(4): 279-293.

Bruun, E. 2005. Bus rapid transit and light rail: Comparing operating costs with a parametric cost model. Transportation Research Record 1927: 11-21.

Chien, S., and Z. Qin. 2004. Optimization of bus stop locations for improving transit accessibility. Transportation Planning and Technology 27(3): 211-227.

Demetsky, M., and B. Lin. 1982. Bus stop location and design. Transportation Engineering Journal 108(4): 313-327.

Fitzpatrick, K., Perkinson, D., and K. Hall. 1997. Findings from a survey on bus stop design. Journal of Public Transportation 1(3): 17-27.

Furth, P., and J. SanClemente. 2006. Near side, far side, uphill, downhill: Impact of bus stop location on bus delay. Transportation Research Record 1971: 66-73.

Furth, P., M. Maaza, and J. SanClemente. 2007. Stop spacing analysis using geographic information system tools with parcel and street network data. Transportation Research Record 2034: 73-81. 
Grant, M., L. Ecola, and W. Messenger. 2007. Transportation Demand Management Programs as an Emission Reduction Strategy: New Challenges and Opportunities. ICF International, Fairfax, VA.

Gutierrez, J., and J. C. Gracia-Palomares. 2008. Distance-measure impacts on the calculation of transport service areas using GIS. Environment and Planning B: Planning and Design 35(3): 480-503.

Harford, J. 2006. Congestion, pollution, and benefit-to-cost ratios of U.S. public transit systems. Transportation Research Part D: Transport and Environment 11(1): 45-58.

Hellinga, B., and L. Fu. 1999. Assessing expected accuracy of probe vehicle travel time reports. Journal of Transportation Engineering 125(6): 524-530.

Karlaftis, M., and P. McCarthy. 1999. The effect of privatization of public transit costs. Journal of Regulatory Economics 16(1): 27-43.

Kennedy, C. 2002. A comparison of the sustainability of public and private transportation systems: Study of the greater Toronto area. Transportation 29(4): 459-493.

Kenworthy, J. 2008. An international review of the significance of rail in developing more sustainable urban transport systems in higher income cities. World Transport Policy \& Practice 14(2): 21-37.

Kihl, M., D. Brennan, N. Gabhawala, J. List, and P. Mittal. 2005. Livable Communities: An Evaluation Guide. AARP Public Policy Institute, Washington, DC.

Kittelson \& Associates. 2003. Transit Capacity and Quality Service Manual. Transportation Research Board, Washington, DC.

Kocur, G., and C. Hendrickson. 1982. Design of local bus service with demand equilibrium. Transportation Science 16(2): 149-170.

Kuah, G., and J. Perl. 2001. Optimization of feeder bus routes and bus stop spacing. Journal of Transportation Engineering 114(3): 341-354.

Lilly, C. 1984. Diesel Reference Book. Butterworths, Boston, MA.

Litman, T. 2002. Evaluating transportation equity. World Transport Policy \& Practice $8(2): 50-65$.

Litman, T. 2004. Transit price elasticities and cross-elasticities. Journal of Public Transportation 7(2): 37-58. 
Litman, T. 2007. Smart Congestion Reductions II: Reevaluating the Role of Public Transit for Improving Urban Transportation. Victoria Transport Policy Institute, Victoria, BC.

Litman, T. 2008. Valuing transit service quality improvements. Journal of Public Transportation 11(2): 43-64.

Litman, T. 2009. Transportation cost and benefit analysis: Techniques, estimates and Implications. Victoria Transport Policy Institute, Victoria, BC.

Litman, T., and E. Doherty. 2009. Transportation Cost and Benefit Analysis: Techniques, Estimates and Implications. Victoria Transport Policy Institute, Victoria, BC.

Marsden, G., and P. Bonsall. 2006. Performance targets in transport policy. Transport Policy 13(3): 191-203.

McElroy, J., P. Remington, A. Trentham-Dietz, S. Robert, and P. Newcomb. 2003. Geocoding addresses from a large population-based study: Lessons learned. Epidemiology 14(4): 399-407.

Metropolitan Washington Council of Governments. 2010. Air Quality Conformity Determination of the 2010 Constrained Long Range Plan and the FY2011-2016 Transportation Improvement Program for the Washington Metropolitan Region. Metropolitan Washington Council of Governments, Washington, DC.

Murray, A. 2001. Strategic analysis of public transport coverage. Socio-Economic Planning Sciences 35: 175-188.

Murray, A. 2003. A coverage model for improving public transit system accessibility and expanding access. Annals of Operations Research 123: 143-156.

Murray, A., and X. Wu. 2003. Accessibility tradeoffs in public transit planning. Journal of Geographical Systems 5: 93-107.

National Research Council. 1991. Rethinking the Ozone Problem in Urban and Regional Air Pollution. National Academy Press, Washington, DC.

National Research Council. 1995. Expanding Metropolitan Highways: Implications for Air Quality And Energy Use. National Academy Press, Washington, DC.

National Transit Database. 2008. City of Fairfax CUE bus (CUE). Accessed April 19, 2012, http://www.ntdprogram.gov/ntdprogram/pubs/profiles/2008/agency_ profiles/3058.pdf. 
Neff, J., and L. Pham. 2007. A Profile of Public Transportation Passenger Demographics and Travel Characteristics Reported in On-Board Surveys. American Public Transportation Association, Washington, DC.

Okabe, A., T. Satoh, T. Furuta, A. Suzuki, and K. Okano. 2008. Generalized network Voronoi diagrams: Concepts, computational methods, and applications. International Journal of Geographical Information Science 22(9): 965-994.

Phillips, R., J. Karachepone, and B. Landis. 2001. Multi-Modal Quality of Service Project. Florida Department of Transportation, Tallahassee, FL.

Polzin, S. 1999. Transportation/land-use relationship: Public transit's impact on land-use. Journal of Urban Planning and Development 125(4): 135-151.

Pratt, R. 2000. Traveler Response to Transportation System Changes: Interim Handbook. Richard H. Pratt, Garrett Park, MD.

Rajbhandari, R., S. Chien, and J. Daniel. 2003. Estimation of bus dwell times with automatic passenger counter information. Transportation Research Record 1841: 120-127.

Rood, T. 1999. Local index of transit availability (LITA). 1997 ITE International Conference.

Saka, A. 2001. Model for determining optimum bus-stop spacing in urban areas. Journal of Transportation Engineering 127(3): 195-199.

Savage, K. 2009. Benefit/Cost Analysis of Converting a Lane for Bus Rapid Transit. Transportation Research Board, Washington, DC.

Srinivasan, K., and P. Jovanis. 1996. Determination of number of probe vehicles required for reliable travel time measurement in urban network. Transportation Research Record 1537: 5-22.

Stradling, S., M. Carreno, T. Rye, and A. Noble. 2007. Passenger perceptions and the ideal urban bus journey experience. Transport Policy 14(4): 283-292.

United States Environmental Protection Agency. 2003. MOBILE6 Inventories and Documentation. Accessed May 7, 2012, http://www.mde.state.md.us/assets/ document/appendixB.pdf.

United States Environmental Protection Agency. 2009. National Emissions Inventory (NEI): air pollutant emissions trends data. Accessed May 7, 2012, http:// www.epa.gov/ttn/chief/trends/index.html\#table. 
Wirasinghe, S., and N. Ghoneim. 1981. Spacing of bus-stops for many-to-many travel demand. Transportation Research Record 15: 210-221.

Ziari, H., M. Keymanesh, and M. Khabiri. 2007. Locating stations of public transportation vehicles for improving transit accessibility. Transport 22(2): 99-104.

\section{About the Authors}

RANJAY M.Shrestha, M.A. (rshresth@masonlive.gmu.edu) is a doctoral student in the Department of Geography and Geoinformation Science at George Mason University.

Edmund J. Zolnik, Ph.D. (ezolnik@gmu.edu) is an Assistant Professor in the School of Public Policy at George Mason University. 